Please Cite as:

Kaplani E., Kaplanis S. (2020) PV Module Temperature Prediction at Any Environmental Conditions and Mounting Configurations. In: Sayigh A. (eds) Renewable Energy and Sustainable Buildings.

Innovative Renewable Energy. Springer, Cham

https://doi.org/10.1007/978-3-030-18488-9 77

\title{
PV module temperature prediction at any environmental conditions and mounting configurations
}

\author{
E. Kaplania, ${ }^{\star \star}$, S. Kaplanis ${ }^{b}$ \\ ${ }^{a}$ Engineering, Faculty of Science, University of East Anglia, Norwich, NR4 7TJ, UK \\ ${ }^{\mathrm{b}}$ Renewable Energy Systems Lab, Technological Educational Institute of Western Greece, \\ Meg. Alexandrou 1, Patra 26334, Greece \\ ${ }^{*}$ Corresponding author. Email: e.kaplani@uea.ac.uk
}

\begin{abstract}
Photovoltaic (PV) module temperature is known to significantly affect its power output and efficiency, while it has been shown to depend mainly on the ambient temperature, the solar irradiance incident on the PV plane and the wind speed, while to a lesser extent on the wind incidence angle and various other environmental parameters as well as PV module structural characteristics, module type, etc. The mounting configuration has been shown to play a significant role in the PV temperature developed and the power output. This paper presents an algorithmic approach for the prediction of PV module temperature at any environmental conditions based on the energy balance equation taking into account PV orientation, windward and leeward side, heat convection by natural and air forced flow, heat conduction and the radiated heat by the PV module. The results are compared to measured data under various outdoor conditions of ambient temperature, solar irradiance and wind speed. In addition, the predicted PV temperature is compared to predicted values from existing models. The robustness of the simulation algorithm developed in the prediction of PV module temperature is presented and its clear advantage over empirical models, which are fine tuned for the exact experimental conditions and/or experimental set ups under which they were developed, is illustrated. Furthermore, the coefficient $f$ which relates the PV module temperature with the solar irradiance on the PV plane and the ambient temperature is examined for various configurations of free-standing fixed and sun-tracking PV system as well as building integrated photovoltaic (BIPV), illustrating essential differences in this and in the temperature developed in the PV module.
\end{abstract}

Keywords: PV temperature prediction, thermal model, energy balance equation, wind speed, BIPV

\section{Introduction}

The effect of PV temperature on the power output, efficiency and final yield of the PV system is significant $[1,2]$. Typical value for the temperature coefficient of maximum power $\mathrm{P}_{\mathrm{m}}$ and similarly for the module efficiency is $-0.5 \% /{ }^{\circ} \mathrm{C}$. A range of $5-25 \%$ reduction in power output is normally expected from the nominal value for $1000 \mathrm{~W} / \mathrm{m}^{2}$ incident irradiance due to PV temperature alone. The effect is in the higher end of the range for BIPV configurations [3]. PV temperature prediction is essential for forecasting PV power output, PV performance analysis, diagnostic purposes, dynamic predictive management of building integrated photovoltaics (BIPV) in Intelligent Energy Buildings [4], etc.

Several empirical and semi-empirical models have been proposed in the research literature providing an estimation of PV temperature, and taking into account ambient temperature $T_{\alpha}$, solar irradiance on the PV plane $I_{T}$ and wind speed $v_{w}$. Some of the well-known models include eq.(1) by King et al. [5], eq.(3) by Faiman [6] while validation of these model's applicability at different climatic regions is presented in [7]. 
$T_{p v, b}=T_{a}+I_{T} \cdot e^{\left(a+b \cdot v_{w}\right)}$

where $T_{p v, b}$ corresponds to the temperature at the back of the module. The cell temperature at the centre is then determined from $T_{p v, b}$ according to [5], based on:

$T_{p v, c}=T_{p v, b}+\Delta T \cdot I_{T} / 1000$

where $\Delta T$ and the empirically determined coefficients $\alpha, b$ in eq.(1) where defined as:

$\mathrm{a}=-3.56, \mathrm{~b}=-0.0750, \Delta \mathrm{T}=3^{\circ} \mathrm{C}$ for glass/cell/polymer sheet, open rack module and $\mathrm{a}=-2.81, \mathrm{~b}=-0.0455, \Delta \mathrm{T}=0^{\circ} \mathrm{C}$ for glass/cell/polymer sheet, insulated back module

In Faiman's model [6] given below, $U_{o}^{\prime}, U_{1}^{\prime}$ are empirically determined coefficients with average values: $U_{o}^{\prime}=25 \mathrm{Wm}^{-2} \mathrm{~K}^{-1}$ and $U_{1}^{\prime}=6.84 \mathrm{Wm}^{-3} \mathrm{sK}^{-1}$.

$T_{p v}=T_{a}+I_{T} /\left(U_{o}^{\prime}+U_{1}^{\prime} \cdot v_{w}\right)$

In another approach, NN-based models have been also proposed such as eq.(4) proposed by Tamizhmani et al. [8] claiming to be independent of site location and technology type:

$T_{p v}=0.943 T_{a}+0.028 I_{T}-1.528 v_{w}+4.3$

Various theoretical models have been also proposed mainly steady-state models based on the Energy Balance Equation (EBE) such as [9], but so far use empirical models for the determination of the air forced convection coefficient. It has been previously shown by the authors in [10] how the air forced convection coefficient estimated by various empirical and theoretical models differs and the extent to which it influences the $T_{p v}$ prediction. The superiority of theoretical models over empirical for the determination of the air forced convection coefficient was highlighted offering wider applicability independent of latitude.

In [10] a simulation model was developed for the determination of $f$ coefficient in eq. (5) based on theoretical expressions of the heat convection coefficients and the Energy Balance Equation:

$T_{p v}=T_{a}+f \cdot I_{T}$

$f=\frac{(\tau \alpha)-\eta_{p v}}{U_{L, f}+U_{L, b}}$

The present paper presents a new simulation model developed for the prediction of PV temperature at any environmental conditions and mounting configurations, considering the solar radiation intensity, ambient temperature, wind velocity, wind incidence angle on the PV surface either front or back and mounting geometry.

\section{PV temperature prediction model}

The proposed simulation model is based on the steady-state energy balance equation, shown in eq.(7). It takes into account heat conduction from the cell to the front glass and back polymer sheet, heat transfer by natural convection for both front and back PV sides at any inclination angle, forced convection coefficient at any PV inclination, orientation, wind direction for the windward and leeward side of the PV module based on theoretically derived 
expressions and, finally, thermal radiation emission for the front and back PV side, taking into account the mounting geometry. The assumptions considered in this model include:

- Temperature of PV module considered uniform

- Thermal capacity of PV module and transient phenomena are neglected. However, the effect of fluctuating wind speed is directly passed onto the temperature of the back PV surface. In these cases the time constant $\mathrm{T}<4 \mathrm{~min}$ of the averaging period so these effects are in fact included.

The simplified thermal electrical equivalent used to determine the unknown temperatures $T_{p v, c}, T_{p v, f}, T_{p v, b}$, is shown in Fig. 1(a). Heat conduction from the cell to the front and back polymer sheet is considered through the thermal resistances $R_{c-f}$ and $R_{c-b}$ which accounts for the sum of the thermal resistances introduced by the various PV layers (Fig. 1(b)). The heat convection coefficients for the front and back PV sides $h_{c, g-a}$ and $h_{c, b-\alpha}$ respectively and the radiative heat transfer coefficients $h_{r, g-a}$ and $h_{r, b-a}$ are taken into account through the overall thermal losses coefficients defined in eq.(8a),(8b).

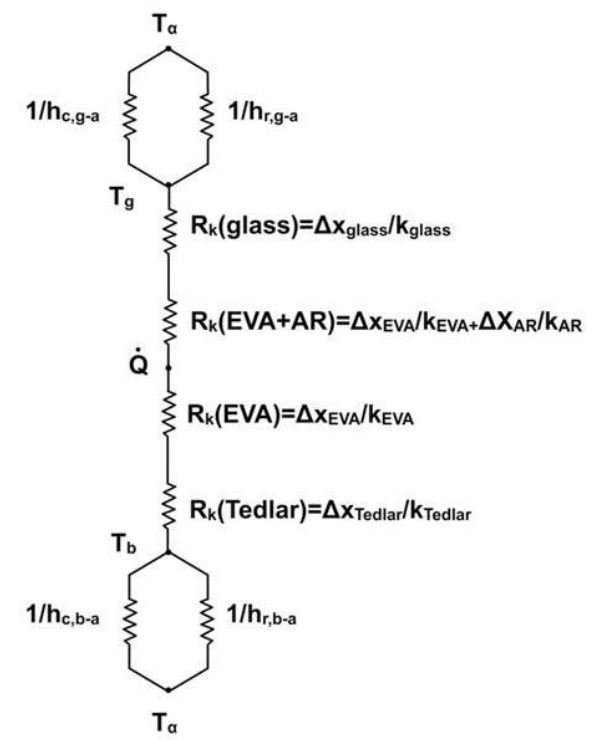

(a)

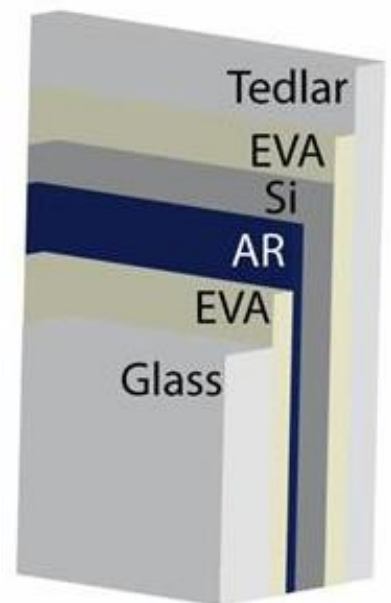

(b)

Figure 1. (a)thermal electrical equivalent, (b) PV module layers.

The steady state energy balance equation becomes:

$$
(\tau \alpha) I_{T}=\eta_{p v} I_{T}+\frac{1}{R_{c-f}+\frac{1}{U_{L, f}}}\left(T_{p v, c}-T_{a}\right)+\frac{1}{R_{c-b}+\frac{1}{U_{L, b}}}\left(T_{p v, c}-T_{a}\right)
$$

where the thermal losses coefficients for the front and back PV side are given by:

$$
\begin{aligned}
& U_{L, f}=h_{c, g-a}+h_{r, g-a} \\
& U_{L, b}=h_{c, b-a}+h_{r, b-a}
\end{aligned}
$$

(та) is the transmission-absorptance product. For the sun-tracking PV system (Ta) is in fact equal to $(\mathrm{T \alpha})_{\mathrm{n}}$. For fixed angle PV system or for BIPV, the (Ta) product is defined through eq.(9a) according to [11], considering the beam, diffuse and ground-reflected irradiance components.

$$
\frac{(\tau \alpha)}{(\tau \alpha)_{n}}=\frac{I_{b} R_{b} \frac{(\tau \alpha)_{b}}{(\tau \alpha)_{n}}+I_{d} \frac{(\tau \alpha)_{d}(1+\cos \beta)}{2(\tau \alpha)_{n}}+r I \frac{(\tau \alpha) r(1-\cos \beta)}{(\tau \alpha)_{n}} 2}{I_{T}}
$$


where the incidence angle modifier (IAM) for the three components is estimated based on eq.(9b) with $b_{0}=0.136$ using the incidence angle $\theta$ for the beam component and the effective angles for the diffuse and ground-reflected radiation according to well-known expressions provided in [11].

$K_{\tau \alpha}=1-b_{o}\left(\frac{1}{\cos \theta}-1\right)$

The natural convection from a PV module is determined through the Nusselt number $\mathrm{Nu}$ separately for the front PV side and for the back PV side considering the cases of all inclination angles $\beta<30^{\circ}$ and $\beta \geq 30^{\circ}$ according to the equations analytically presented in [10]. In these Prandtl $\operatorname{Pr}$ and Rayleigh $R \alpha$ numbers are calculated for the temperature of the boundary layer, at the front and back PV side respectively.

For the forced convection coefficient of the windward side of the module the Sartori's expressions [12] were used, see eq.(10a)-(10c), as demonstrated in [10] to provide very accurate predictions of the $f$ coefficient. The distinction between laminar, fully turbulent and mixed flows was made based on conditions $x d L \geq 0.95, \quad x d L \leq 0.05$ and $x_{d} L<0.95$ respectively. $\mathrm{L}$ is the surface length in the wind direction and $x_{c}$ is the critical length based on the Reynolds number $R e_{x, c}$ and given by: $x_{c}=R e_{x, c} \cdot v / v_{w}$.

$\begin{array}{ll}h=3.83 \cdot v_{w}^{0.5} \cdot L^{-0.5} & \text { for laminar flow } \\ h=5.74 \cdot v_{w}^{0.8} \cdot L^{-0.2} & \text { for fully turbulent flow } \\ h=5.74 \cdot v_{w}^{0.8} \cdot L^{-0.2}-16.46 \cdot L^{-1} & \text { for mixed flows }\end{array}$

For the leeward side of the PV module, the above expressions were considered but with $\mathrm{L}$ now given by $4 \mathrm{~A} / \mathrm{S}$, where $\mathrm{A}$ the area of the module and $\mathrm{S}$ its perimeter.

Combined natural and forced convection was also considered based on the Grashof and Reynolds number comparison according to the following $[13,15]$. For the case of combined convection Churchill's expressions eq.(11a)-(11b) provide a suitable solution with $\mathrm{m}=3$.

- $G r_{L}<\operatorname{Re}_{L}^{2}$ forced convection

- $G r_{L}>>R_{L}^{2}$ natural convection

- $0.01<G r_{L} / R_{L}^{2}<100$ combined

$h_{c, g-a}^{m}=h_{c, g-a(\text { natural })}^{m}+h_{c, g-a(\text { forced })}^{m}$

$h_{c, b-a}^{m}=h_{c, b-a(\text { natural })}^{m} \pm h_{c, b-a(\text { forced })}^{m}$

The radiative heat transfer the respective coefficients for the front $\mathrm{PV}$ side and the back $\mathrm{PV}$ side were considered normalised to the difference between PV temperature and the ambient to correct for the simplification of the thermal electrical equivalent and EBE which take into account radiative heat transfer with respect to the ambient $T_{\alpha}$ rather than the sky $T_{s}$ or ground temperature $T_{\text {grd }}$. Therefore, the normalised coefficients used in the EBE, eqs.(8a),(8b) are given by:

$$
\begin{aligned}
& h_{r, g-a}=\varepsilon_{g} F_{p v, f-s k y} \sigma \frac{T_{p v, f}^{4}-T_{s}^{4}}{T_{p v, f}-T_{a}}+\varepsilon_{g} F_{p v, f-g r d} \sigma \frac{T_{p v, f}^{4}-T_{g r d}^{4}}{T_{p v, f}-T_{a}} \\
& h_{r, b-a}=\varepsilon_{b} F_{p v, b-s k y} \sigma \frac{T_{p v, b}^{4}-T_{s}^{4}}{T_{p v, b}-T_{a}}+\varepsilon_{b} F_{p v, b-g r d} \sigma \frac{T_{p v, b}^{4}-T_{g r d}^{4}}{T_{p v, b}-T_{a}}
\end{aligned}
$$


where the view factors from the PV front or back to the sky and ground respectively are:

$F_{p v, f-s k y}=(1+\cos \beta) / 2$

$F_{p v, f-g r d}=(1-\cos \beta) / 2$

$F_{p v, b-s k y}=(1+\cos (\pi-\beta)) / 2$

$F_{p v, b-g r d}=(1-\cos (\pi-\beta)) / 2$

For the case of BIPV system, the normalised coefficient for the radiative heat transfer at the back PV side which is facing the indoors environment with temperature $T_{\text {ind }}$ is given by:

$h_{r, b-i n d}=\varepsilon_{b} \sigma \frac{T_{p v, b}^{4}-T_{i n d}^{4}}{T_{p v, b}-T_{a}}$

Based on the EBE eq.(7) the determination of $P V$ temperature $T_{p v, c}$ for the free standing systems is achieved through eq.(15).

$T_{p v, c}=\frac{\left((\tau \alpha)-\eta_{p v}\right) I_{T}}{\frac{1}{R_{c-f}+\frac{1}{U_{L, f}}}+\frac{1}{R_{c-b}+\frac{1}{U_{L, b}}}}+T_{a}$

For the BIPV configuration the same theoretical model proposed for the free standing PV system applies for the front PV side considering natural convection, forced convection (windward or leeward) and long-wave radiation, while at the back PV side only natural convection and long-wave radiation apply. In this case, the EBE takes the form of eq.(16) and the $T_{p v, c}$ may be accurately predicted by eq.(17).

$$
\begin{aligned}
& (\tau \alpha) I_{T}=\eta_{p v} I_{T}+\frac{1}{R_{c-f}+\frac{1}{U_{L, f}}}\left(T_{p v, c}-T_{a}\right)+\frac{1}{R_{c-b}+\frac{1}{U_{L, b}}}\left(T_{p v, c}-T_{\text {ind }}\right) \\
& T_{p v, c}=\frac{\left((\tau \alpha)-\eta_{p v}\right) I_{T}+\frac{T_{a}}{R_{c-f}+\frac{1}{U_{L, f}}}+\frac{T_{\text {ind }}}{R_{c-b^{+}}+\frac{1}{U_{L, b}}}}{\frac{1}{R_{c-f^{+}} \frac{1}{U_{L, f}}}+\frac{1}{R_{C-b^{+}+} \frac{1}{U_{L, b}}}}
\end{aligned}
$$

In eqs.(7),(15)-(17), the efficiency $\eta_{p v}$ is considered for the actual conditions of solar irradiance and for the predicted PV temperature according to the following based on $[9,14]$.

$\eta_{P V}=\eta_{S T C} \cdot\left(1+\gamma \cdot\left(T_{P V}-T_{P V, S T C}\right)+\delta \cdot \ln \left(I_{T} / I_{T, S T C}\right)\right)$

with $\eta_{\text {stc }}, T_{\mathrm{PV}, \mathrm{STC}} \mathrm{I}_{\mathrm{T}, \mathrm{STC}}$ the efficiency, $\mathrm{PV}$ temperature and solar irradiance at Standard Test Conditions (STC): $\mathrm{T}_{\mathrm{PV}, \mathrm{STC}}: 25^{\circ} \mathrm{C}, \mathrm{I}_{\mathrm{T}, \mathrm{STC}}: 1000 \mathrm{~W} / \mathrm{m}^{2}$. The temperature coefficient for power $\mathrm{Y}$ is taken equal to $-0.5 \% /{ }^{\circ} \mathrm{C}$ and $\delta$ for poly-crystalline PV modules 0.11 and for mono-crystalline 0.085 [14].

Having predicted the PV temperature at the centre of the cell, the proposed simulation algorithm predicts the PV temperature at the front and back of the PV module according to the following continuity principles:

- thermal losses from cell to glass = thermal losses from cell top to environment

$$
\frac{1}{R_{c-f}}\left(T_{p v, c}-T_{p v, f}\right)=\frac{1}{R_{c-f}+\frac{1}{U_{L, f}}}\left(T_{p v, c}-T_{a}\right)
$$

- Thermal losses cell to back = thermal losses from cell back to environment 
$\frac{1}{R_{c-b}}\left(T_{p v, c}-T_{p v, b}\right)=\frac{1}{R_{c-b}+\frac{1}{U_{L, b}}}\left(T_{p v, c}-T_{a}\right)$

Therefore, the PV temperature at the front glass and at the back PV surface is predicted by:

$T_{p v, f}=\frac{T_{p v, c}+T_{a} R_{c-f} U_{L, f}}{R_{c-f} U_{L, f}+1}$
$T_{p v, b}=\frac{T_{p v, c}+T_{a} R_{c-b} U_{L, b}}{R_{c-b} U_{L, b}+1}$

The simulation algorithm predicts $T_{p v, c}, T_{p v, f}$ and $T_{p v, b}$ iteratively with very fast convergence.

\section{Experimental data}

To test the accuracy of the PV temperature predictions from the proposed simulation model, experimental data were captured from two PV configurations. The first configuration included a two-axis sun-tracking PV system of 4 poly-crystalline Si modules $120 \mathrm{~W}_{\mathrm{p}}$ each, see Fig. 2(a), with PV module parameters monitored on clear-sky days for the duration of a year. These included solar irradiance on the inclined PV plane and module temperature monitored for 4 min every hour. The modules' inclination and orientation range tested as realised by the sun-tracking system during the year were: $15^{\circ} \leq \beta \leq 85^{\circ}$ and $75^{\circ} \leq \gamma_{P V} \leq 285^{\circ}$. Additionally the environmental parameters monitored were global and diffuse solar irradiance at horizontal, ambient temperature, wind speed and wind direction in $1 \mathrm{~min}$ intervals. The wind speed was corrected to the module height. The two stations were synchronized and 4 min averages of the above parameter values were extracted.

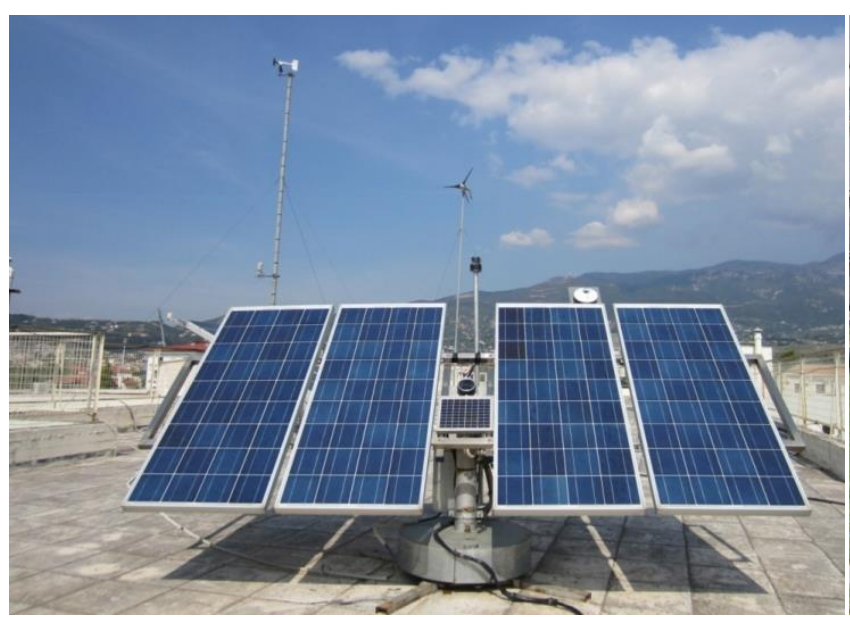

(a)

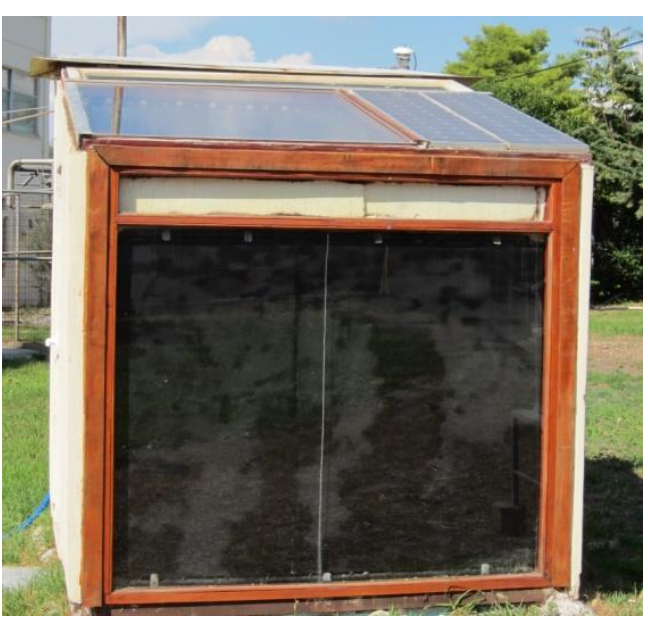

(b)

Figure 2. (a) two-axis sun-tracking PV system, (b) BIPV test cell

The second configuration included a BIPV experimental test cell comprising of 2 monocrystalline Si modules $55 \mathrm{~W}_{\mathrm{p}}$ each integrated on the rooftop of the test cell at an inclination angle $\beta=15^{\circ}$ and South-orientation $\mathrm{YPV}_{\mathrm{PV}} 0^{\circ}$, see Fig.2(b). The same environmental parameters as above were recorded at $1 \mathrm{~min}$ intervals, as well as the following BIPV parameters monitored PV module temperature at the back of the modules, solar irradiance on the inclined PV plane and room temperature. The stations were synchronized and data averaged for the same period. 


\section{Results and analysis}

The simulation results from the proposed model with the two-axis sun-tracking PV system are shown in Figs.3, 4 for 3 consecutive days in January and in July. The PV module temperatures at the cell, front and back surface of the PV module were predicted and display higher cell temperature by $0.5-1^{\circ} \mathrm{C}$ from that of the back surface which in turn is higher by up to $1^{\circ} \mathrm{C}$ from the front PV glass. It is observed that during high wind speed conditions the front and back PV temperatures coincide (see for example Fig. 4 for wind speed $6 \mathrm{~m} / \mathrm{s}$ ).

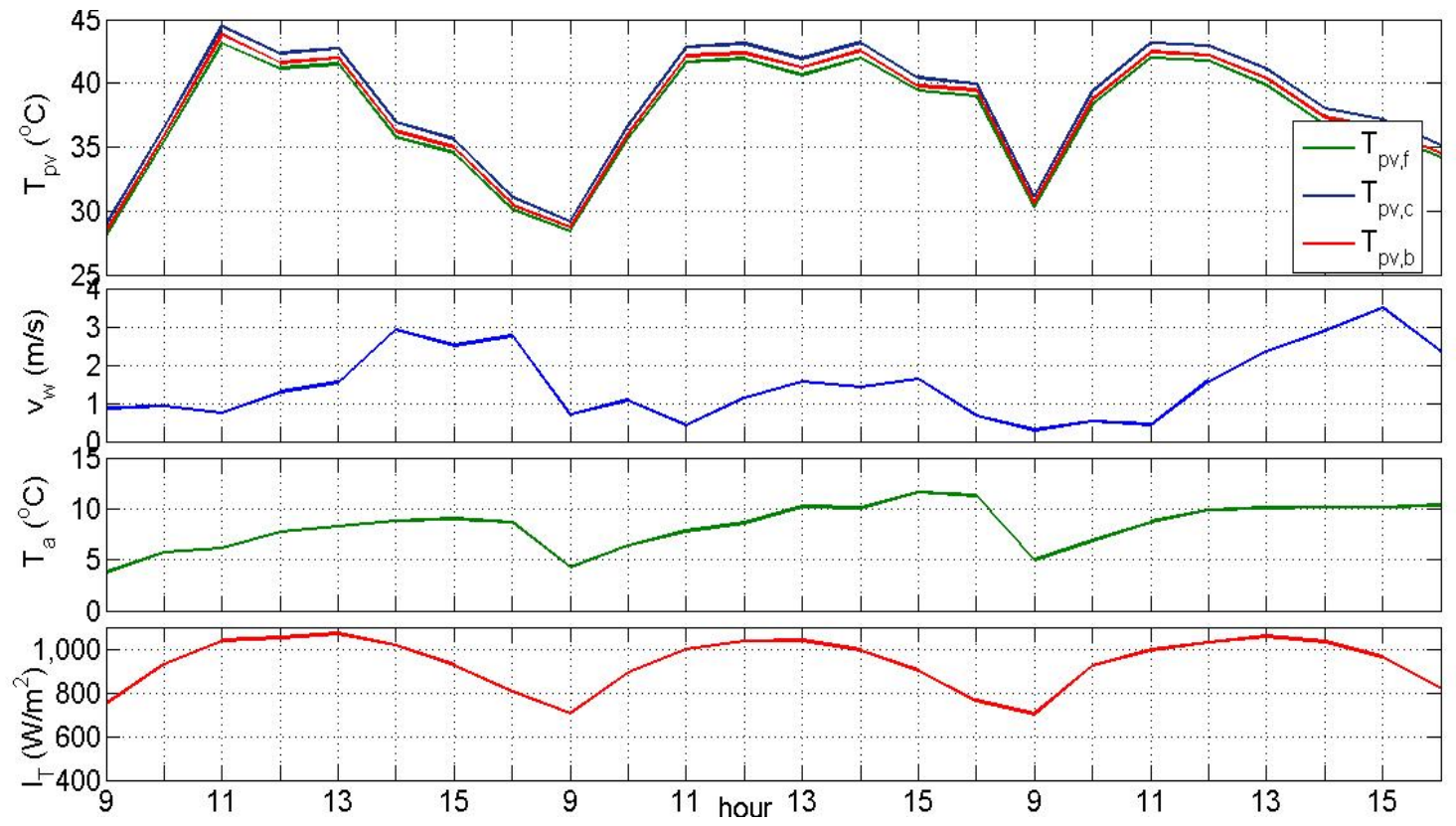

Figure 3. $P V$ temperature at the cell $T_{p v, c}$, back surface $T_{p v, b}$ and front glass $T_{p v, f}$ predicted by the simulation algorithm for the sun-tracking PV system during 3 consecutive days in January. The wind speed $\mathrm{V}_{\mathrm{w}}$, ambient temperature $\mathrm{T}_{\mathrm{a}}$ and solar irradiance on $\mathrm{PV}$ plane $\mathrm{I}_{\mathrm{T}}$ are shown in the subplots.
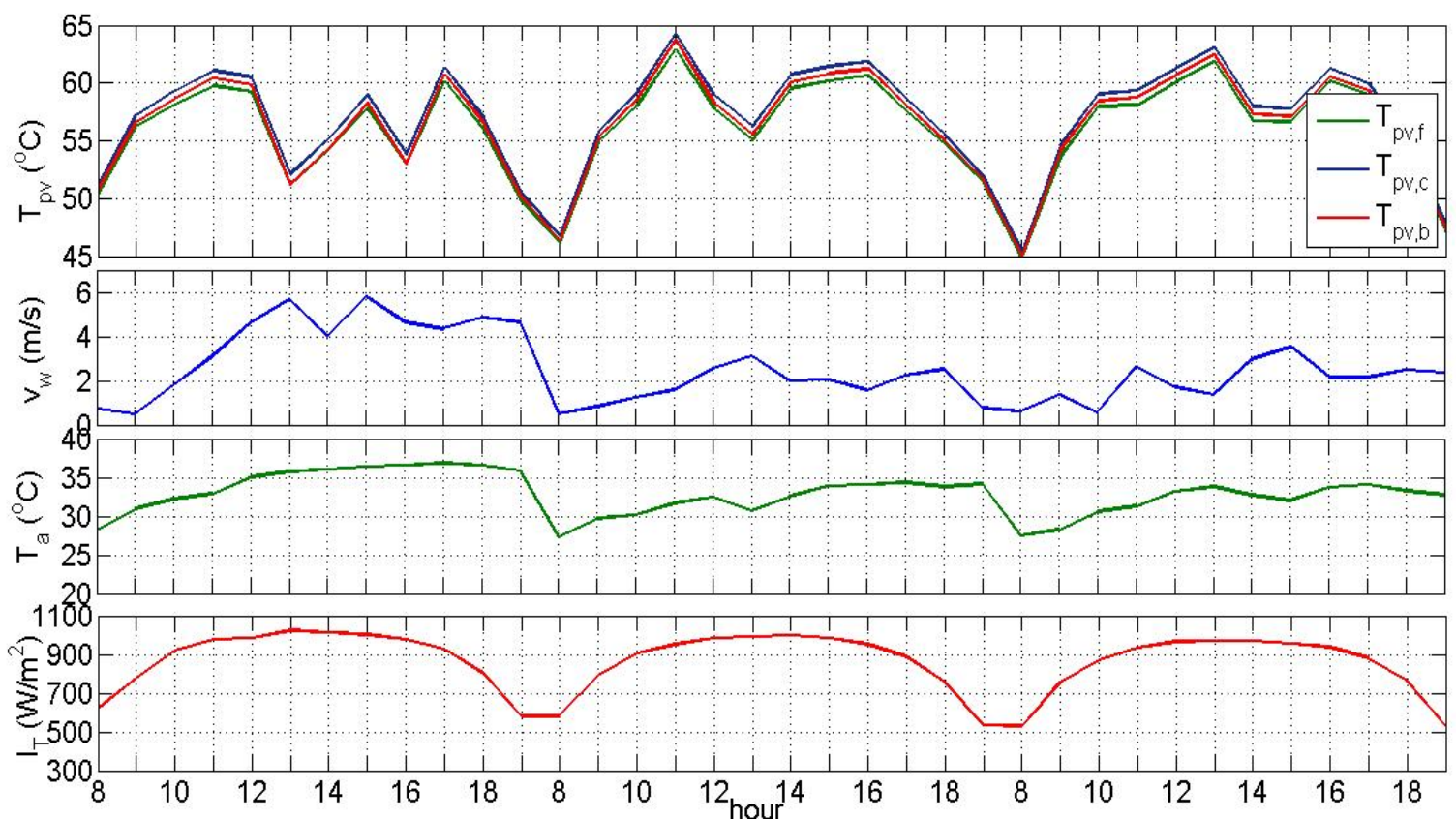

Figure 4. Same as Fig. 3 for 3 consecutive days in July. 
The predicted PV temperature by the simulation algorithm lies very close to the measured values as shown in Figs. 5 and 6 and outperforms the other well known models $[5,6,8]$. It is noteworthy that Faiman's model shows good predictions particularly at low wind speeds, while larger deviations are observed for mid to high wind speeds. Mani's model shows very good performance in July as shown in Fig.6.

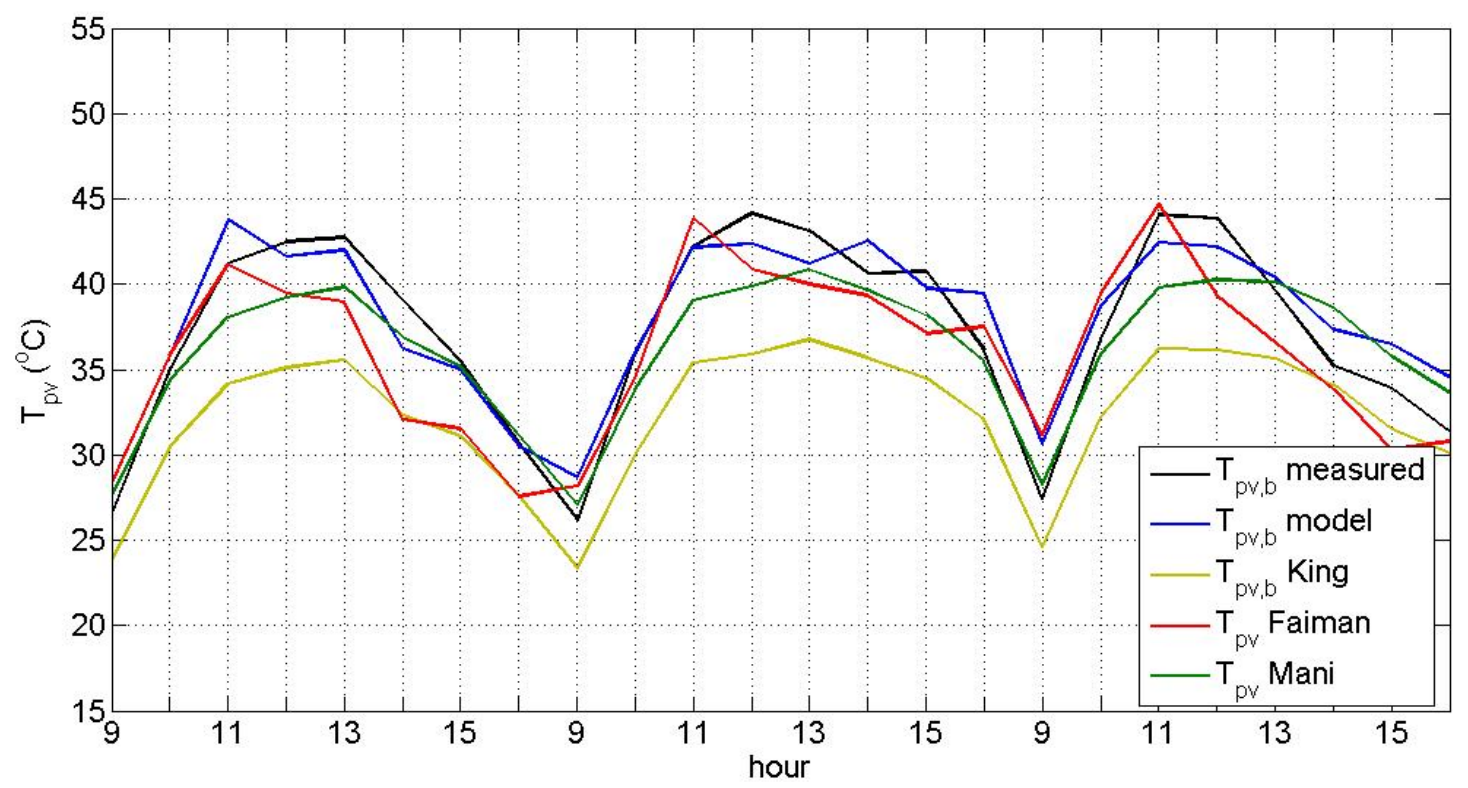

Figure 5. Comparison of the predicted PV temperature by the proposed simulation algorithm with measured data and predictions by other well-known models $[5,6,8]$ for the 3 consecutive days in January (see Fig. 3 for the environmental parameters during this period).

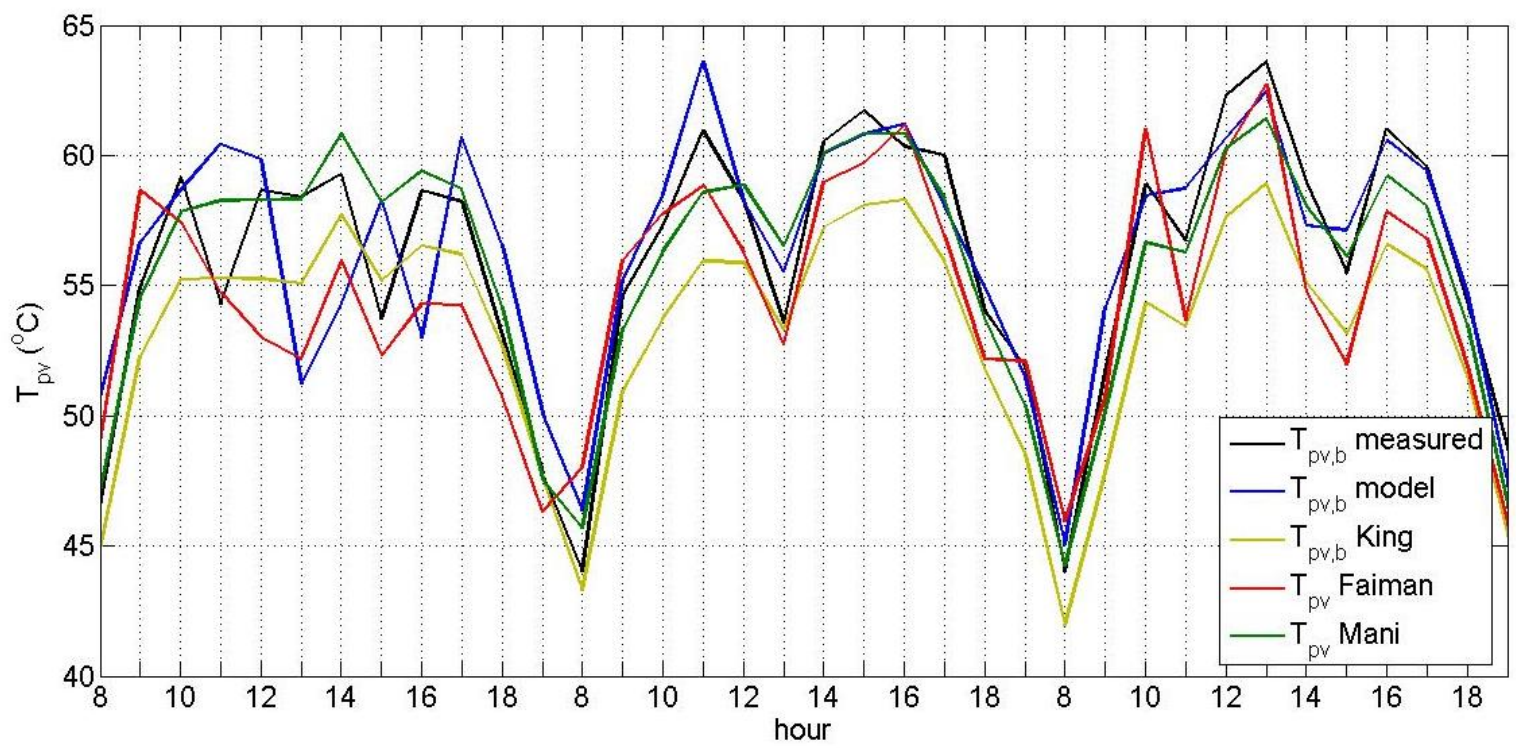

Figure 6. Same as Fig. 5 but for the 3 consecutive days in July (see Fig. 4 for the environmental parameters during this period).

The PV temperature predicted for the BIPV configuration, shows the back PV temperature from the cell temperature to be between $0-0.5^{\circ} \mathrm{C}$ lower and the front glass temperature to be up to $2^{\circ} \mathrm{C}$ lower than the cell temperature, with higher differences observed when the front side is windward and lower when leeward (Fig.7). The predicted PV temperature by the simulation algorithm lies very close to the measured values as shown in Fig.8 and outperforms the other models. The other models improve somewhat at very low wind 
speeds. It is noted that the coefficients $\alpha, b$ in King's model eq.(1) were those corresponding to the insulated back in the case of the BIPV configuration. As shown the PV temperature generally follows the solar irradiance profile, with wind speed playing also a significant role.

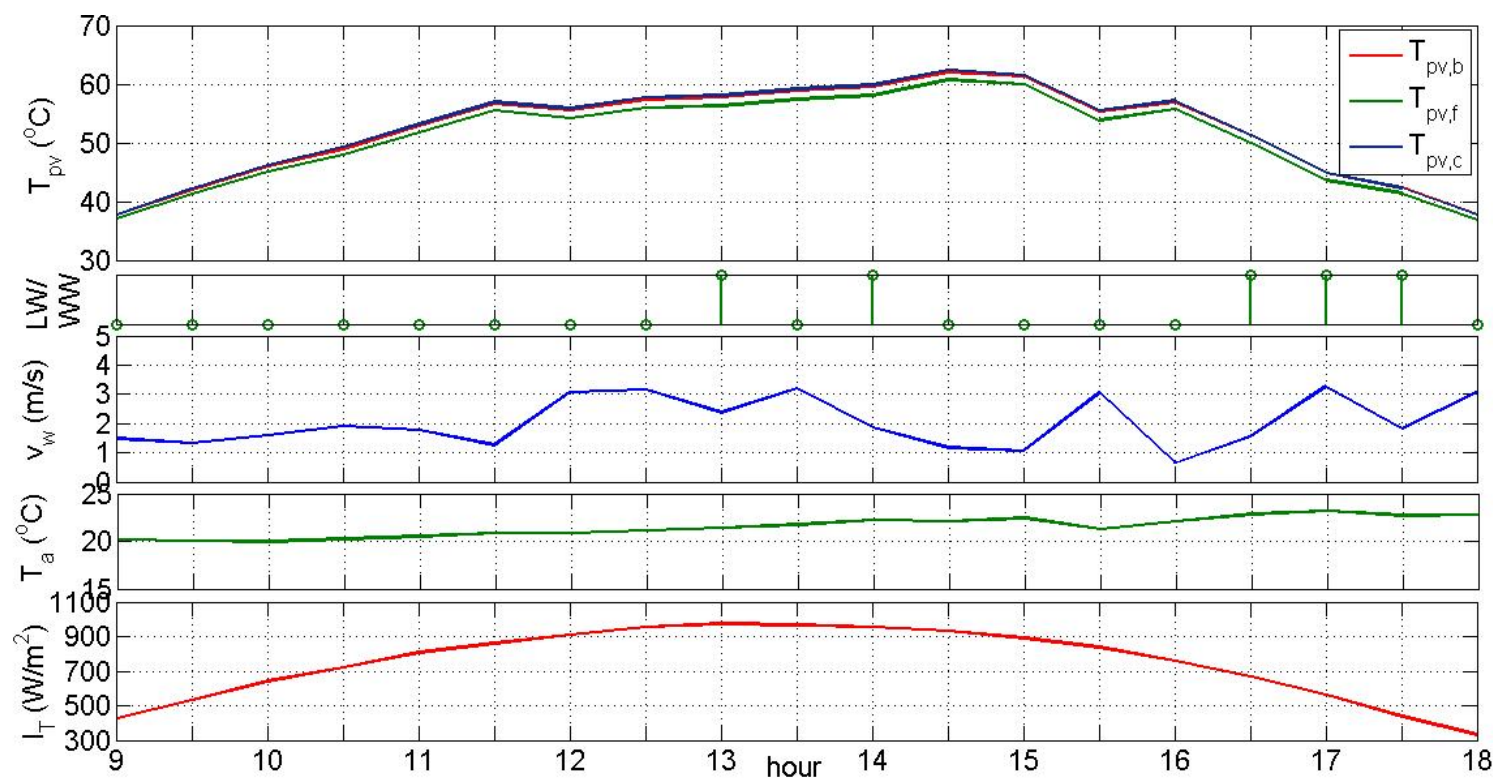

Figure 7. $\mathrm{PV}$ temperature at the cell $T_{\mathrm{pv}, \mathrm{c}}$, back surface $T_{\mathrm{pv}, \mathrm{b}}$ and front glass $T_{\mathrm{pv}, \mathrm{f}}$ predicted by the simulation algorithm for the BIPV configuration for a day in May. The wind speed $\mathrm{V}_{\mathrm{w}}$, ambient temperature $\mathrm{T}_{\mathrm{a}}$ and solar irradiance on PV plane $\mathrm{I}_{\mathrm{T}}$ and whether the front side is leeward (LW) displayed as 0 or windward (WW) as 1, are shown in the subplots.

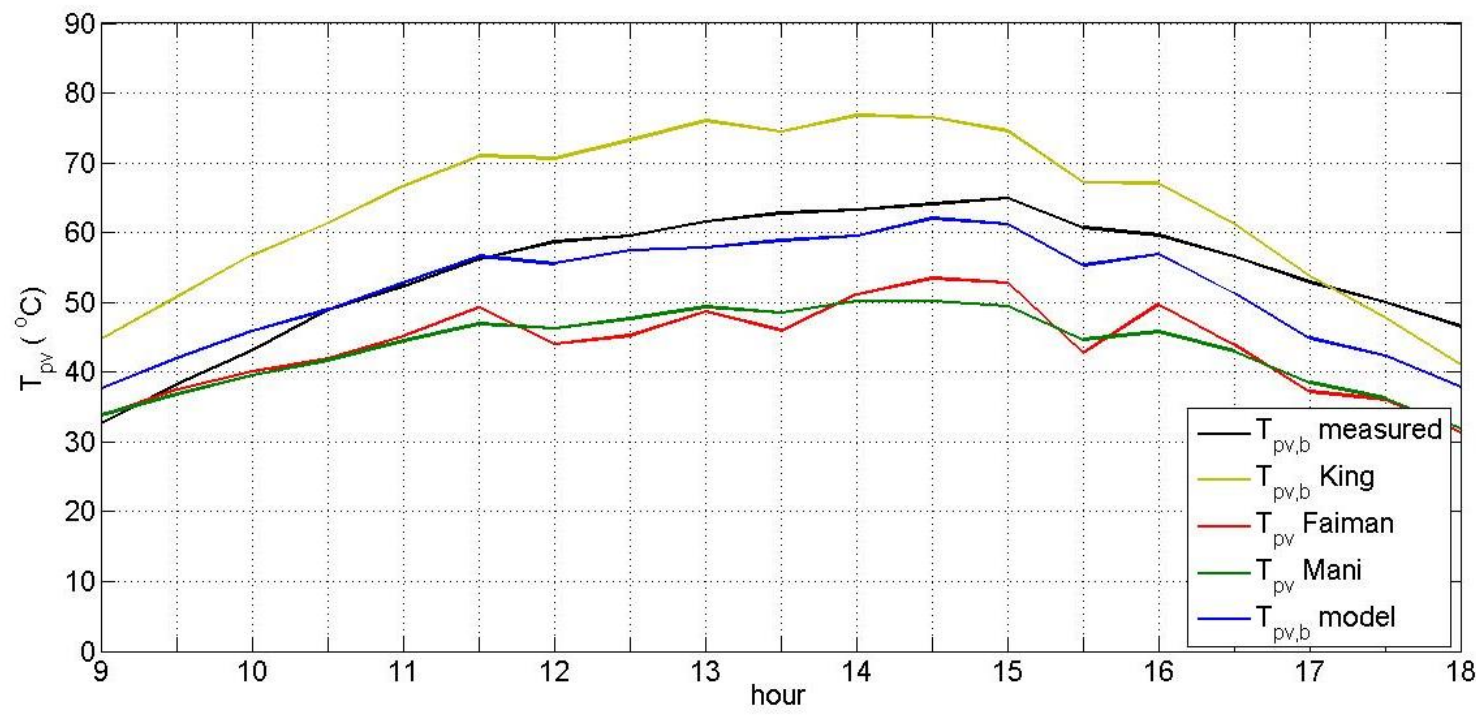

Figure 8. Comparison of the predicted PV temperature by the proposed simulation algorithm with measured data and predictions by other well-known models $[5,6,8]$ for a day in May (see Fig.7 for the environmental parameters during this period).

\section{Conclusions}

The thermal model developed and presented is theoretical, analytical and predicts PV temperature at the cell, front glass and back surface with high accuracy. The results were validated with measured data captured for the duration of 1 year from a sun-tracking PV 
system and also from a BIPV system. It was tested for a wide range of inclination angles, orientations, and environmental conditions including solar irradiance, ambient temperature, wind speed and wind direction. The model results were also compared with those produced by some of the well know models empirical, semi-empirical, NN-based, and was shown in general to outperform them. Empirical models are very easy to apply but in most cases are fine tuned to the experimental set-up, location, technology type, mounting configuration, at which the empirical parameters were derived. Theoretical models give an advantage over the empirical models and may be successfully applied for any PV module orientation, inclination, environmental conditions, mounting configurations. The estimated air forced convection coefficient significantly affects the prediction of temperature and therefore it is important the coefficient is theoretically derived. Sartori's equations used in the simulation model provided an excellent estimate of the air forded convection coefficient. The thermal radiation emission from the front and the back of the PV module is another critical component that needs to be included in the prediction models, whereas several existing models neglect this.

The robustness of the simulation algorithm developed in the prediction of PV module temperature was presented and its clear advantage over empirical models was illustrated. Further work is currently carried out in including transient phenomena related to fluctuations in the solar irradiance.

\section{References}

[1] King, D.L., Kratochvil, J.A., Boyson, W.E., 1997. Temperature coeffficients for PV modules and arrays: Measurement, methods, difficulties and results. In: Proc. 26th IEEE Photovoltaic Specialists Conf. Anaheim, California, Sept 29- Oct 3.

[2] Skoplaki, E., Palyvos, J.A., 2009. On the temperature dependence of photovoltaic module electrical performance: A review of efficiency/power correlations. Solar Energy 83, 614-624.

[3] Kaplanis, S. Kaplani, E. 2014. On the relationship factor between the PV module temperature and the solar radiation on it for various BIPV configurations. AIP Conference Proceedings 1618, 341 (2014); doi: 10.1063/1.4897744.

[4] Kaplanis, S. Kaplani, E. 2015. Intelligent energy buildings based on RES and nanotechnology. AIP Conference Proceedings 1702, 150005 (2015); doi: 10.1063/1.4938926.

[5] King, D.L., Boyson, W.E., Kratochvil, J.A., 2004. Photovoltaic array performance model, SANDIA Report, SAND2004-3535, Sandia National Laboratories, New Mexico.

[6] Faiman, D., 2008. Assessing the outdoor operating temperature of photovoltaic modules. Progress in Photovoltaics: Research and Applications, 16, 307-315.

[7] Koehl, M., Heck, M., Wiesmeier, S., Wirth, J., 2011. Modeling of the nominal operating cell temperature based on outdoor weathering, Solar Energy Materials \& Solar Cells, 95, 1638-1646.

[8] Tamizhmani G., Ji L., Tang Y., Petacci L., Osterwald C., 2003. Photovoltaic module thermal/wind performance: Long term monitoring and model development for energy rating. NREL/CD-52033586, 936-939.

[9] Mattei M., Notton G., Cristofari C., Muselli M., Poggi P. Calculation of the polycrystalline PV module temperature using a simple method of energy balance. Renewable Energy, 2006, 31, 553567.

[10] Kaplani E., Kaplanis S., 2014. Thermal modelling and experimental assessment of the dependence of PV module temperature on wind velocity and direction, module orientation and inclination. Solar Energy, 107, 443-460.

[11] Duffie J.A., Beckman W.A., 2013. Solar engineering of thermal processes. 4th ed. Wiley, USA.

[12] Sartori, E., 2006. Convection coefficient equations for forced air flow over flat surfaces. Solar Energy 80, 1063-1071.

[13] White, F.M., 1988. Heat and Mass Transfer, Addison-Wesley Publishing, USA.

[14] Anderson, A.J., 1996. Photovoltaic translation equations: A new approach. In: Final Subcontract Report NREL/TP-411-20279.

[15] Churchill, S.W., 1977. A comprehensive correlating equation for laminar, assisting, forced and free convection, AIChE Journal, 23(1), 10-16. 